\title{
Optimization of Mechanical Properties of Silver Nanoparticles (AgNPS)-Loaded Chitosan/Polylactic Acid (PLA) Biofilms by Using Response Surface Methodology (RSM)
}

\author{
A. Shaari ${ }^{1}$, M.N. Abu Seman ${ }^{1, a}$ and C.K.M. Faizal ${ }^{2}$ \\ ${ }^{1}$ Faculty of Chemical Engineering \& Natural Resources, Universiti Malaysia Pahang (UMP), Lebuhraya Tun Razak, \\ 26300 Gambang, Kuantan, Pahang, Malaysia. \\ ${ }^{2}$ Faculty of Engineering Technology, Universiti Malaysia Pahang (UMP), Lebuhraya Tun Razak, 26300 Gambang, \\ Kuantan, Pahang, Malaysia.
}

\begin{abstract}
Fabrication of silver nanoparticles-loaded chitosan-polylactic acid based biofilms was successfully employed for investigating the optimal of mechanical properties (i.e. tensile strength and elongation at break) of biofilms using central composite design (CCD), response surface methodology (RSM). In this study, only two factors that influences the biofilm mechanical properties were selected namely concentration of polyethelene glycol 400 (PEG) and percentage volume of polylactic acid (PLA)/chitosan. Analysis of results was performed by using response surface methodology (RSM) to avoid the traditional one-factor-at-a-time experiments. Common statistical tools such as analysis of variance (ANOVA) and response surface plot were used to determine the optimal tensile strength and elongation at break responses. Central composite design (CCD) builds a response surface for mechanical properties of biofilms optimization. From the results of statistical analysis, it could be concluded that the optimal conditions for mechanical properties of biofilms were $7.93 \% \mathrm{w} / \mathrm{w}$ concentration of polyethylene glycol (PEG) and $28.79 \% / 71.21 \%$ percentage volume of polylactic acid (PLA)/chitosan. At this optimum stage, $7.99 \mathrm{MPa}$ of tensile strength and $32.6 \%$ elongation at break were obtained. Then, results of verification process have shown that the percentage errors are $2.08 \%$ for tensile strength and $3.89 \%$ elongation at break, respectively.
\end{abstract}

\section{Introduction}

Recently, high demands and low cost of production are the reasons of synthetic polymer has become increasingly valuable [1] especially in food packaging and medical field. These synthetic polymers are not biodegradable; it is finally end up in landfill sites and produce very harmful gases that can cause environmental pollutions and soil contaminations. The burning of synthetic polymers can cause the release of dioxin which is highly toxic that will cause chronic disease (i.e: cancer) through inhalation. Therefore, it is very crucial to discover other biodegradable films to replace the use of synthetic polymer. The biodegradable films were not meant to totally substitute the synthetic polymers. Nevertheless, the using of biodegradable films as packaging materials is still one of the most hopeful

\footnotetext{
${ }^{\mathrm{a}}$ Corresponding author: mazrul@ump.edu.my
} 
approaches for effective methods of maintaining in food quality and medical application. By using the biodegradable films for food product packaging and medical field, the industry are facing with the problems of short shelf life period due to low antimicrobial resistance [2]. Due to that, the inclusion of the active compounds in the films becomes an innovative approach in order to avoid food product contamination by microbial [3]. Silver nanoparticles have been broadly used as antimicrobial agents in food packaging purposes [4]. However, biodegradable films with incorporation of silver nanoparticle products based on one types of biofilms, possess many disadvantages, mainly attributed to brittle nature of films and poor mechanical properties. In order to improve mechanical properties, these films can be modified by several methods such as blending with other natural polymers such as polylactic acid (PLA) and chitosan [5]. Thus, the aim of this research was to optimize mechanical properties of chitosan/PLA/AgNPs. For optimization purpose, RSM approach was applied where a set of experiment was designed using CCD.

\section{Materials and Method}

\subsection{Materials}

Chitosan flakes from crab shells were purchased from Fisher Scientific, polyethylene glycol (PEG) 400, polylactic acid (PLA) (pellet form), chloroform and acetic acid were supplied from Sigma Aldrich. Silver nanoparticles (AgNPs) were obtained from our lab. The preparation of silver nanoparticles from tea extract solution was described in previous paper [6].

\subsection{Film preparation}

Method of chitosan/PLA blend film were prepared as described by [7] with some modifications. To prepare blend films of chitosan and PLA, solution of chitosan and PLA were mixed separately in different solutions before blending. One percent $(w / v)$ PLA was dissolved in chloroform and $1 \%(w / v)$ chitosan was dissolved in $1 \%(v / v)$ acetic acid and both of them were stirred under magnetic stirring for 2 hours respectively. The various concentration of PEG 400 (in $\% w / w$ ) were then added into both solutions separately and stirred for 1 hour. Then both solutions were blended homogeneously with silver nanoparticles colloids solution. The concentration of silver nanoparticles in the film was fixed at $23.08 \% w / w$ based on the finding from the antibacterial test as reported in our previous paper [6]. The various compositions ratios percentage volume of chitosan/PLA and concentration of PEG 400 were listed in the Table 1. The preparation was filtered and degassed under room pressure $(101.325 \mathrm{kPa})$. The blends films were prepared by casting on glass Petri dishes (1- $m m$ thickness) and evaporated at $35^{\circ} \mathrm{C}$ for 18 hours.

\subsection{Tensile measurement}

The analysis of mechanical properties of the blended films was carried out by using tensile machine (Shimadzu Model Autograph AG-X instrument) according to ASTM D882 standard [8]. Tensile strength $(\mathrm{MPa})$ and elongation at break $(\%)$ were involved in this mechanical analysis. Five films were stored at $25^{\circ} \mathrm{C}$ for 24 hours before measurement were conducted. The analyzed area of films (gage length $=50 \mathrm{~mm}$ ) were unaxially stretched at a fixed velocity of $500 \mathrm{~mm} / \mathrm{min}$ which the width and thickness of the films were measured before testing. The results of the experiment were computer recorded.

\subsection{Experimental design by Central Composite Design (CCD)}

Central composite design was used determine the optimum factors and to analyse the response pattern of mechanical properties of biofilms. The range selected for the concentration of polyethylene glycol 
(PEG) and percentage volumes of PLA/chitosan were determined according to the restriction that previously experienced during screening the effects and interactions of operational parameters on the films using full factorial design (FFD) [9]. The independent variable for the concentration of polyethylene glycol (PEG) is represented by variable $A$ ranging from 5 to $25 \%$, while the percentage volumes of PLA/chitosan $B$ ranged from 20 to $80 \%$, respectively. Based on computer simulation, a total of 12 runs were established including 1 replicate of factorial design, 4 replicate central point and 1 star points $(\alpha=1.414)$.

\section{Results and Discussion}

\subsection{Design of experiment by CCD}

Table 1 shows the levels and ranges of analysis process parameters (A: concentration of PEG and B: percentage volume of PLA/chitosan) that influencing the responses (mechanical properties) and the responses results of observed in the experiment.

Table 1. Experimental layout and results of $2^{2}$ full factorial CCD

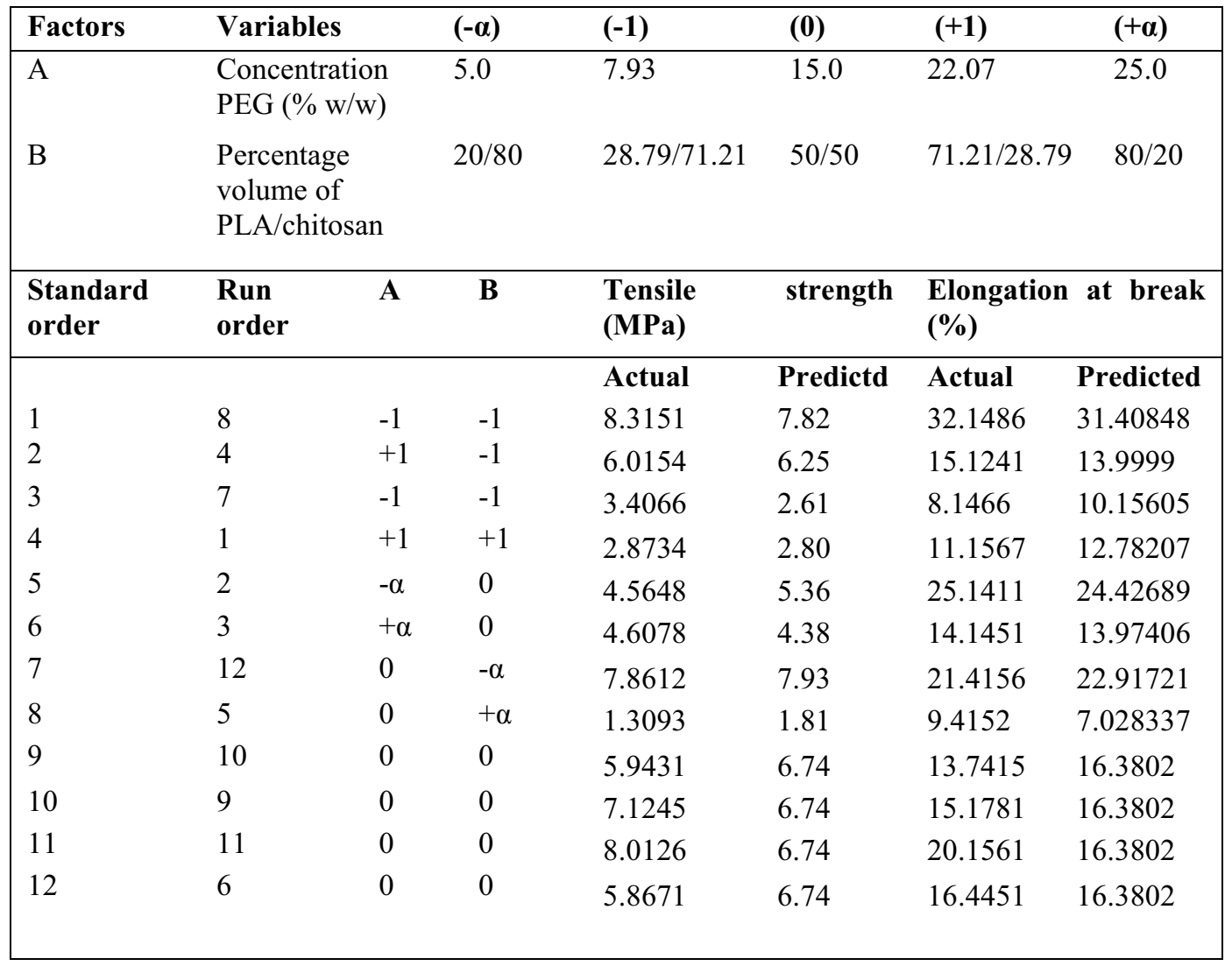

In this design, the quadratic model for predicting the optimal point was according to Eq. 1.

$$
Y=\mathrm{b}_{0}+\Sigma \mathrm{b}_{\mathrm{i}} \mathrm{x}_{\mathrm{i}}+\Sigma \mathrm{b}_{\mathrm{ii}} \mathrm{x}_{\mathrm{i}}^{2}+\Sigma \mathrm{b}_{\mathrm{ij}} \mathrm{x}_{\mathrm{i}} \mathrm{x}_{\mathrm{j}}
$$


where $Y$ is the response variable, $b$ is the regression coefficient of the model, and $x$ is the coded levels of the independent variables. The Design Expert software version 7.1.6. (Stat-Ease Inc., Minneapolis, USA) was used to develop the experimental plan and optimize the regression equation (Eq.1).

The multiple regression equations describe the mechanical properties of films response using concentration of polyethylene glycol (PEG) and percentage volume of PLA/chitosan as the main variable in terms of coded variables are shown by Eq. 2 and Eq.3:

Tensile Strength $=+6.736825-0.34651 \mathrm{~A}-2.16454 \mathrm{~B}+0.441625 \mathrm{AB}-0.93355 \mathrm{~A}^{2}-0.93408 \mathrm{~B}^{2}$

Elongation at Break $=+16.3802-3.69564 \mathrm{~A}-5.61757 \mathrm{~B}+5.00865 \mathrm{AB}+1.410138 \mathrm{~A}^{2}-0.70371 \mathrm{~B}^{2}$

The empirical model equation Eq.1 forms a mathematical correlation model that can be employed to predict and optimize the tensile strength and elongation at break of films within the range of variable factors of this experiment. The response values determined by means of empirical models were compared to the experimental data designed in Table 1 as predicted value. The results are shown in Table 1 for both the tensile strength and elongation at break responses. The response models (RS Model) show good fits to the experimental data. Therefore, the model can be considered adequate for the predictions and for further investigation of optimization purpose.

\subsection{Response surface plot}

In order to investigate the effects of the parameter on mechanical properties of films, the three dimensional and contour plots were used. Figure 1 depict the interaction between concentration of polyethylene glycol (PEG) (A) and percentage volume of PLA/chitosan (B) for response tensile strength in the form of three-dimensional display of the response surface, contour plot and interaction graph.

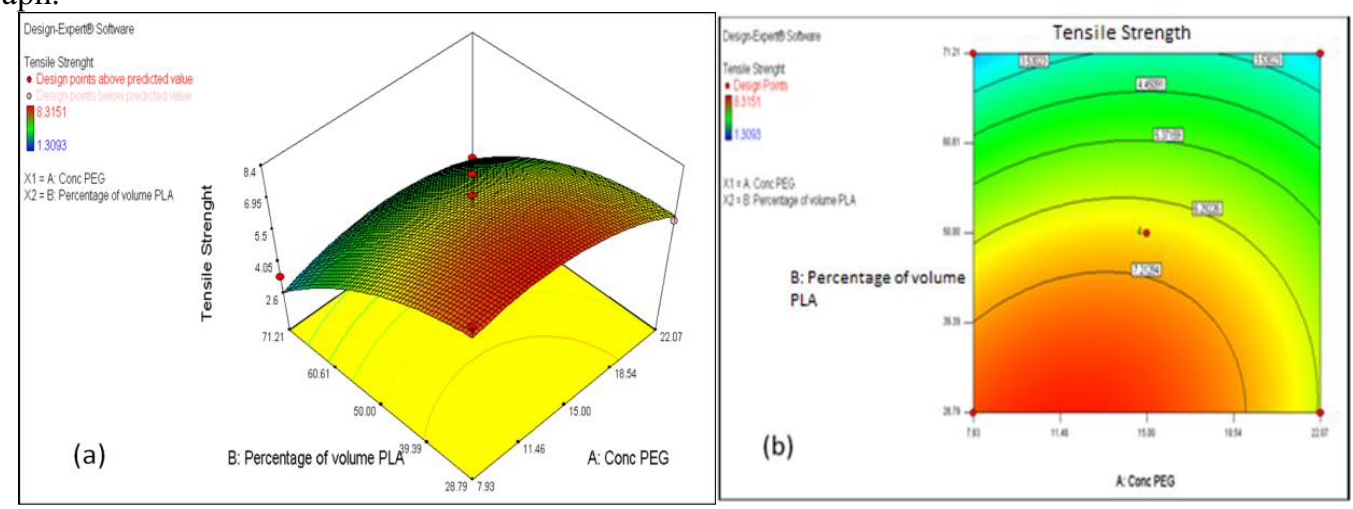

Figure 1. Interactions of polyethylene glycol (PEG) concentration (A) and percentage volume of PLA/chitosan (B) on response tensile strength by (a) response surface curve, (b) contour plot graph

The effect of the polyethylene glycol (PEG) concentration and percentage volume of PLA/chitosan on the tensile strength of films was depicted in Figure 1. This figure demonstrates that the tensile strength of films have reached the maximum value $(8.32 \mathrm{MPa})$ at $(7.93 \%)$ concentration of polyethylene glycol (PEG) and (28.79\%) percentage volume of PLA/ $(71.21 \%)$ chitosan. The curvature of the Figure 1 (a) indicated that both concentration of polyethylene glycol (PEG) and percentage volume of PLA/chitosan had quadratic effect on the tensile strength.

Figure 2 illustrates the interactions between concentration of polyethylene glycol (PEG) (A) and percentage volume of PLA/chitosan (B) for response elongation at break in the form of threedimensional display of the response surface, contour plots and interaction graphs. The effect of the concentration of polyethylene glycol (PEG) and percentage volume of PLA/chitosan on the elongation at break of films was depicted in this figure. This figure validates that the elongation at break of films 
have reached the maximum results $(32.15 \%)$ at (7.93 \%) concentration of polyethylene glycol (PEG) and $(28.79 \%)$ percentage volume of PLA/ $(71.21 \%)$ chitosan.
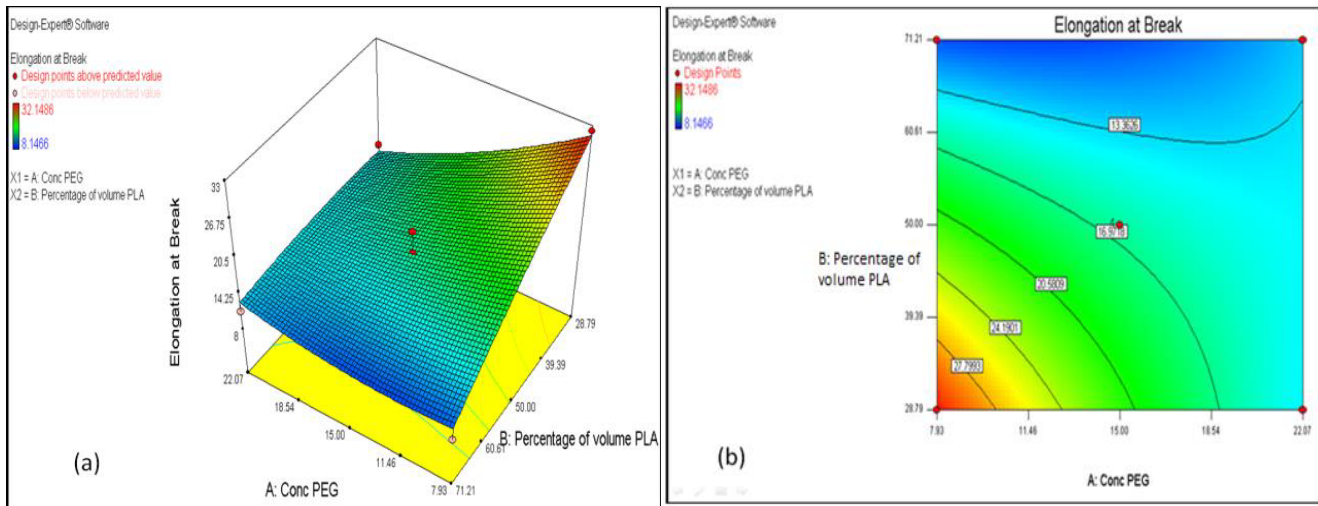

Figure 2. Interaction of concentration of polyethylene glycol (PEG) (A) and percentage volume of PLA/chitosan (B) on response elongation at break by (a) response surface curve, (b) contour plot graph

There was no curvature in Figure 3 (a) indicates that both concentration of polyethylene glycol (PEG) and percentage volume of PLA/chitosan had no quadratic effect on the tensile strength. As discussed in the literature review regarding polyethylene glycol (PEG), as plasticizer, polyethylene glycol (PEG) reduced the intermolecular forces and resulted in reduced tensile strength but increased in percentage value of elongation [10]. Moreover, increasing of polylactic acid (PLA) in the films induced in order to decrease the tensile strength and elongation at break. This is due to the increment of polylactic acid (PLA) concentration, the content of the unreacted monomer and the oligomer also increased, resulting in the deformation of the strong hydrogen bond between the chitosan chains, thus the tensile strength and elongation at break of crude films decreased [11].

\subsection{Validation and confirmation run of empirical model adequacy}

It must be identified that in a multi-response situation, the excellent condition is when each individual desirability function and the overall desirability D is unity $(=1)$. Note that if an individual desirability function is completely undesirable, then the overall desirability value is zero [12]. From the software results, with overall desirability of $\mathrm{D}=0.949$ (near the perfect value of 1), the obtained optimal conditions are $7.93 \% \mathrm{w} / \mathrm{w}$ and $28.79 \%$ for concentration of polyethylene glycol (PEG) and percentage volume of PLA/chitosan, respectively.

To check the prediction accuracy, the empirical model needs to be validated. This could be achieved by the developing of regression equation in predicting the mechanical properties of films at any particular concentration of polyethylene glycol $(\mathrm{PEG})(\% \mathrm{w} / \mathrm{w})$ and percentage volume of PLA/chitosan (\%) within the range of level defined previously. The confirmation runs were carried out by using optimal conditions as suggested by the software (Table 2). Results of Table 2 have shown that the percentage errors are ranging from $2.08 \%$ for tensile strength and $3.89 \%$ elongation at break, respectively. Thus implied that the empirical model developed were considerably accurate for responding terms as the percentage error between the actual and predicted values were well within the value of 5\% [13]. By this means further analysis with regards to ideal operational process for optimal mechanical properties of film would be based on this developed model. 
Table 2. The results of verification process

\begin{tabular}{|c|c|c|c|c|c|}
\hline \multicolumn{2}{|c|}{$\begin{array}{l}\text { Run Factor as suggested by the } \\
\text { software }\end{array}$} & \multicolumn{4}{|c|}{ Tensile strength (MPa) } \\
\hline $\begin{array}{l}\text { Concentration of } \\
\text { polyethylene } \\
\text { glycol (PEG) } \\
(\% \mathrm{w} / \mathrm{w})\end{array}$ & $\begin{array}{l}\text { Percentage } \\
\text { volume of } \\
\text { PLA/chitosan (\%) }\end{array}$ & Actual & Predicted & Residual & Error \\
\hline \multirow[t]{3}{*}{7.93} & \multirow[t]{3}{*}{28.79} & 7.99 & 7.82 & 0.17 & $2.08 \%$ \\
\hline & & \multicolumn{4}{|c|}{ Elongation at break (\%) } \\
\hline & & $\begin{array}{l}\text { Actual } \\
32.6\end{array}$ & $\begin{array}{l}\text { Predicted } \\
31.41\end{array}$ & $\begin{array}{l}\text { Residual } \\
1.27\end{array}$ & $\begin{array}{l}\text { Error } \\
3.89 \%\end{array}$ \\
\hline
\end{tabular}

\section{Conclusions}

Data from the optimization process indicates that the optimal conditions for mechanical properties of films were $7.93 \% \mathrm{w} / \mathrm{w}$ concentration of polyethylene glycol (PEG) and $28.79 \% / 71.21 \%$ percentage volume of polylactic acid (PLA)/chitosan. At this optimum stage, $7.99 \mathrm{MPa}$ of tensile strength and $32.6 \%$ elongation at break were obtained. Results of verification process have shown that the percentage errors are ranging from $2.08 \%$ for tensile strength and $3.89 \%$ elongation at break, respectively. Thus implied that the empirical model developed were considerably accurate for responding terms as the percentage error between the actual and predicted values were well within the value of $5 \%$.

\section{Acknowledgment}

The authors wish to express their thanks to University Malaysia Pahang and Ministry of Education Malaysia for sponsoring Aznizan postgraduate's study via MyBrain15.

\section{References}

1. T.M. Wu, C.Y. Wu, Polym. Degrad. Stab. 91 (2006).

2. M. Aider, LWT - Food Sci. and Tech. 43 (2010).

3. W.Guiga, S. Galland, E. Peyrol, P. Degraeve, A. Carnet-Pantiez, I. Sebti, Inno. Food Sci. and Emerg. Technol. 10 (2009) .

4. R. Yoksan, S. Chirachanchai, Mat. Sci. Eng. C. 30, 6 (2010).

5. E.Salleh, I.Muhamad, N. Khairuddin, Asian Chitin Journal 3 (2007).

6. A. Shaari, M.N.A. Seman, C.K.M.F.C. Ku, World Research \& Innovation Convention on Engineering \& Technology 2012, Kuala Lumpur, Malaysia, 3-5 December 2012.

7. F.Sebestian, G. Ste, A. Copinet, V. Coma, Carb. Pol. 5, 2 (2006).

8. J.W. Vernice, A. Mayer, S.J. Bailey, N.C. Baldini, S. Emery, J. Ermigiotti, B. Huffman, M.A. Olcese, K.A. Peters, J.L. Rosiak, D.A. Terruso, E.A. Whealen, “ASTM Packaging Standards and Related Technical Material 7th Edition," ASTM International, West Conshohocken, PA, 2007.

9. A. Shaari, M.N.A. Seman, C.K M.F.C. Ku, Proceeding of International Conference on Science, Technology and Social Science, Kuantan, Pahang, 20-22 November 2012; 757-765.

10. P.C. Srinivasa, M.N. Ramesh, Tharanathan, Food Hyd., 21, 7 (2007) .

11. F.Yao, W. Chen, H. Wang, H. Liu, K. Yao, P. Sun, H. Lin, Polymer, 44, 21 (2003) .

12. M. Khayet, M.N. Abu Seman, N., Hilal, J. Mem. Sci. 349 (2010) .

13. A.W. Zularisam, A.F. Ismail, M.R. Salim, M. Sakinah, T. Matsuura, Sep. Pur. Technol. 65, 2 (2009). 